EM

\title{
ESPAÇO GEOGRÁFICO, LUGAR E PAISAGEM: CONSTRUÇÃO COLETIVA DE SABERES NA APAE DE BRUSQUE/SC ${ }^{1}$
}

\author{
GEOGRAPHIC SPACE, PLACE AND LANDSCAPE: COLLECTIVE \\ CONSTRUCTION OF KNOWLEDGE AT APAE IN BRUSQUE/SC
}

\author{
Vanderleia GEMELLI ${ }^{2}$
}

\begin{abstract}
Resumo: O presente artigo busca elucidar alguns aspectos relacionados ao curso "O espaço geográfico em transformação: espaço vivido e as práticas espaciais - contribuições para a inclusão social", oferecido aos usuários do projeto Serviço Profissionalizante da Associação de Pais e Amigos dos Excepcionais (Apae) de Brusque/SC. O objetivo central do curso desenvolvido, foi de proporcionar aos envolvidos condições para agirem enquanto cidadãos ativos e transformadores de sua realidade, através do conhecimento acerca do espaço geográfico em que estão inseridos, contribuindo também para a melhora cognitiva para o mundo do trabalho. Para tanto utilizou-se como metodologia a construção coletiva dos conceitos de espaço geográfico, lugar e paisagem, a partir do espaço vivido de cada aluno, partindo para outras escalas de análise, através do uso de imagens, documentários e aula de campo. As estratégias utilizadas possibilitaram aos alunos correlacionar os diferentes espaços por eles vividos, entendendo-se enquanto agentes que criam e transformam esses espaços de vivência, proporcionando assim contribuições para a sua emancipação, inclusão social e profissional e exercício da cidadania.
\end{abstract}

Palavras-Chave: Espaço vivido; Conceitos geográficos; Transformação espaciais.

Abstract: The present article aims at clarifying some aspects related to the course "The geographic space in transformation: lived space and the spatial practices - contributions for the social insertion", offered to the users of project Vocational Service of Parents and Friends Association of Special Needs People (Apae) from Brusque/SC. The central aim of the course developed was at proposing for those involved conditions to act while active citizens and transformers of their reality, through the knowledge around the geographic space where they are inserted, also contributing to the cognitive improvement for the working market. For that, it was used as methodology the collective construction of geographic space concepts, place and landscape, from the lived space of each student, going on to other analysis scale, through the use of images, documentaries and field lessons. The used strategies made possible to the students correlate the different spaces lived by them, understood as agents that create and transform those living spaces, thereby providing contributions for their emancipation, social and professional insertion and citizenship exercise.

Keywords: Lived space; Geographical concepts, Spatial transformation.

\section{Introdução}

Vivemos em um contexto onde diversos segmentos sociais buscam diariamente sua melhoria de vida, emancipação e inclusão social. Nesse sentido, os avanços alcançados pelas

\footnotetext{
${ }^{1}$ O presente artigo resulta de um relato de experiência do curso "O espaço geográfico em transformação: espaço vivido e as práticas espaciais - contribuições para a inclusão social”, desenvolvido junto aos usuários do projeto Serviço Profissionalizante da Associação de Pais e Amigos dos Excepcionais (Apae) de Brusque/SC. O referido curso foi desenvolvido entre os meses de agosto a outubro de 2018.

${ }^{2}$ Mestre em Geografia. Professora de Geografia do Ensino Básico Técnico e Tecnológico do Instituto Federal Catarinense - Campus Brusque.
} 
pessoas portadoras de deficiência intelectual são garantidos pela constituição vigente como direitos.

O espaço escolar constitui-se num ambiente que contribui sobremaneira nesse processo de inclusão e fortalecimento da pessoa com deficiência, tendo em vista que é o espaço onde se desenvolve o saber, mediado pelo professor, mas também enriquecido pelos próprios sujeitos envolvidos no processo, uma vez que os seus saberes, as suas experiências e as trocas realizadas entre os diferentes sujeitos, contribuem no processo de ensino e aprendizagem. Nesse processo, os sujeitos envolvidos, adquirem conhecimentos que contribuem para sua formação pessoal e para a vida em sociedade, constituindo-se enquanto cidadãos.

A Apae - Associação de Pais e Amigos dos Excepcionais, enquanto entidade que atende pessoas com deficiência intelectual ou múltipla, tem como um de seus objetivos a melhoria das condições de vida da pessoa portadora de deficiência, proporcionando-lhe seu desenvolvimento pessoal e assegurando-lhe seus direitos.

Em Brusque - SC, a Apae foi fundada em 1955 por Carlos Moritz e Ruth de Sá Moritz. Ao longo desses mais de 60 anos, os serviços prestados pela instituição buscam contribuir para a manutenção e o desenvolvimento das habilidades físicas, sociais, emocionais e intelectuais de seus usuários, promovendo a qualidade de vida, a emancipação e a inclusão social.

Nesta instituição também há suporte voltado para a qualificação para o mundo do trabalho por meio do projeto Serviço Profissionalizante, que contribui como alternativa para a inclusão social por meio do trabalho.

Nesse sentido, o Instituto Federal Catarinense - Campus de Brusque, através de parceria firmada com a Apae, oferece Cursos de Qualificação Profissional aos usuários da instituição. Dentro dessa parceria, o Curso "O espaço geográfico em transformação: espaço vivido e as práticas espaciais - contribuições para a inclusão social”, foi ofertado aos usuários da Apae, integrantes do projeto Serviço Profissionalizante, entre os meses de agosto e outubro de 2018.

O curso de qualificação profissional teve como objetivo principal proporcionar aos envolvidos condições para agirem enquanto cidadãos ativos e transformadores de sua realidade, através do conhecimento acerca do espaço geográfico em que estão inseridos, contribuindo assim para a melhora cognitiva para o mundo do trabalho. Além disso, o curso também buscou permitir aos alunos correlacionar os diferentes espaços por eles vividos, entendendo-se enquanto atores que criam e transformam esses espaços, para tanto explorou-se a construção do conhecimento acerca de alguns conceitos e conteúdos geográficos.

$\mathrm{O}$ presente artigo busca elucidar alguns aspectos relacionados ao trabalho desenvolvido junto aos alunos da Apae, bem como trazer apontamentos acerca das contribuições para a inclusão social e profissional destes, através da análise espacial.

\section{Procedimentos Metodológicos}

O curso teve carga horária total de 40 horas, sendo que os encontros ocorreram semanalmente, nas terças e sextas-feiras na fase inicial, e nas quintas e sextas-feiras na fase final, de agosto a outubro de 2018. Foi ofertado aos usuários do Serviço Profissionalizante da Apae de Brusque, sendo que estes possuem idades entre 18 e 35 anos, e apresentam deficiência intelectual em diferentes níveis.

Durante as aulas que foram ministradas, as professoras da instituição acompanharam as atividades realizadas, contribuindo sobremaneira para potencializar o desenvolvimento de 
conhecimentos e habilidades de cada aluno, estimulando-os a superarem seus limites.

Considerando que o ensino-aprendizagem na educação especial pressupõe metodologias diferenciadas, que permitam o desenvolvimento da aprendizagem de acordo com o nível cognitivo do aluno, Franciosi; Torres (2013) apontam que os alunos com deficiência intelectual "[...] apresentam níveis diferentes e acentuados de aprendizagem e necessitam de um trabalho pedagógico com metodologias específicas, recursos pedagógicos diferenciados [...]" (FRANCIOSI; TORRES, 2013, p.3).

Nesse sentido, a prática pedagógica desenvolvida durante o Curso de Qualificação Profissional junto aos alunos da Apae de Brusque, buscou priorizar o espaço de vivência dos alunos e o uso de imagens que permitissem aos alunos a possibilidade de ampliação do conhecimento para além da escala local. Ainda conforme Franciosi; Torres (2013), a escola "[...] é um local privilegiado onde sujeitos diferentes, que têm histórias de vida e aprendizagem individuais se encontram, trocam experiências e pela ação mediadora do professor produzem e consolidam conhecimentos." (FRANCIOSI; TORRES, 2013, p.2).

Considerando a metodologia preconizada, após apresentada a estrutura do curso aos alunos, a abordagem inicial realizada foi no sentido de desvendar "o que é a Geografia", enquanto ciência que tem como objeto principal de estudo, o espaço geográfico.

Essa abordagem fez-se necessária considerando a compreensão acerca do espaço geográfico enquanto:

[...] uma totalidade, a exemplo da própria sociedade que lhe dá vida [...] o espaço deve ser considerado como um conjunto de funções e formas que se apresentam por processos do passado e do presente [...] o espaço se define como um conjunto de formas representativas de relações sociais do passado e do presente e por uma estrutura representada por relações sociais que se manifestam através de processos e funções (SANTOS, 1978, p. 122).

Ou seja, entende-se que a compreensão acerca do resultado das ações humanas na transformação do espaço vivido, é essencial para que os estudantes se reconheçam enquanto seres que criam e modificam o espaço em que estão inseridos, em diferentes escalas. Para melhor compreensão foram apresentadas, em power point, diversas imagens para demonstrar as transformações do espaço geográfico, tais como imagens comparativas das mesmas áreas em épocas diferentes, imagens representativas de diferentes atividades econômicas, imagens de campo e cidade, bem como imagens que retratam problemas ambientais e sociais. Ao observar as imagens, os alunos foram instigados a analisar a aparência (descrição) e a essência (relações, sentidos) das diferentes paisagens, compreendendo que estas não são apenas formas em si, mas que possuem relações e sentidos, que podem ser observados através das cores, sons, odores, movimentos e outros atributos sensoriais.

Dando sequência aos conteúdos trabalhados durante o curso, e contemplando os apontamentos levantados pelos representantes da instituição (Apae), no que se refere a alinhar os temas trabalhados com os objetivos do projeto de Serviço Profissionalizante da Apae, bem como alinhá-los às necessidades dos alunos, o próximo tema trabalhado foi "orientação e localização". Um dos objetivos do projeto de Serviço Profissionalizante da Apae é estimular nos alunos a locomoção independente, para que estes possam se locomover entre os diferentes espaços que frequentam de maneira independente. Para tanto trabalhou-se em sala a orientação pelo sol, os pontos cardeais e colaterais, a localização de Brusque dentro do estado de Santa Catarina, e deste dentro do Brasil. Para potencializar os conhecimentos adquiridos com o tema trabalhado, os alunos elaboraram um mapa mental de um trajeto conhecido por eles. A imagem 1 abaixo demonstra alguns resultados dessa atividade: 
EM

QUESTÃO

V.13 N. $03 \bullet 2020$

pág. 71-83

\section{Imagem 1 - Atividade "Mapa Mental”.}

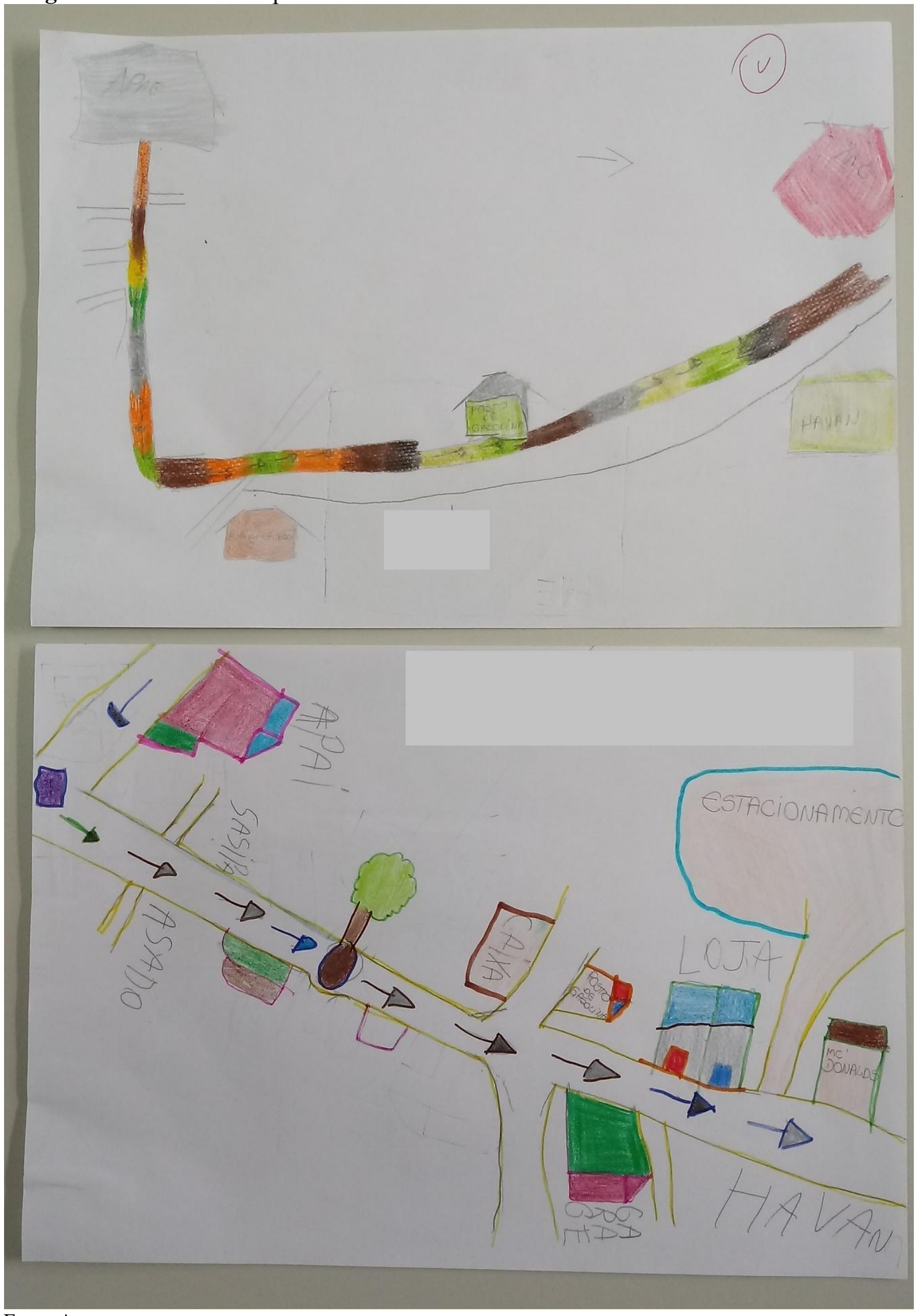


Outro desdobramento relacionado ao tema "orientação e localização", foi a realização de um trabalho de campo voltado para a questão da locomoção independente. Nessa atividade selecionou-se um dos roteiros ${ }^{3}$ do transporte coletivo de Brusque, sendo que ao longo do trajeto os alunos foram estimulados a observar aspectos diversos, tais como transformações do espaço geográfico, sons, cores, odores, movimentos (que se apresentaram diferentes em áreas centrais e periféricas), presença ou não de elementos naturais, diferenças entre áreas urbanas e rurais, diferentes atividades econômicas, dentre outros. Além disso, durante o trabalho de campo, em diversos pontos do trajeto os alunos foram questionados com relação à localização dos mesmos, bem como qual orientação seguir para se deslocar até outros determinados pontos.

Dentro dessa temática, foi possível trabalhar ainda noções de orientação, com base na orientação pelo movimento aparente do sol. Inicialmente os alunos preencheram a Rosa dos Ventos (conforme imagem 2 a seguir), e realizaram a demonstração da orientação pelo sol (braço direito para a direção onde o sol "nasce" pela manhã, braço esquerdo para a direção em que o sol "se põe" à tarde, à frente o norte e nas costas o sul). Depois foram questionados sobre a direção de diversos pontos, com relação à sala de aula onde se encontravam, tais como secretaria, sala de informática, portaria, quadra, dentre outros.

Imagem 2 - Atividade "Rosa dos Ventos e Orientação Pelo Sol”.

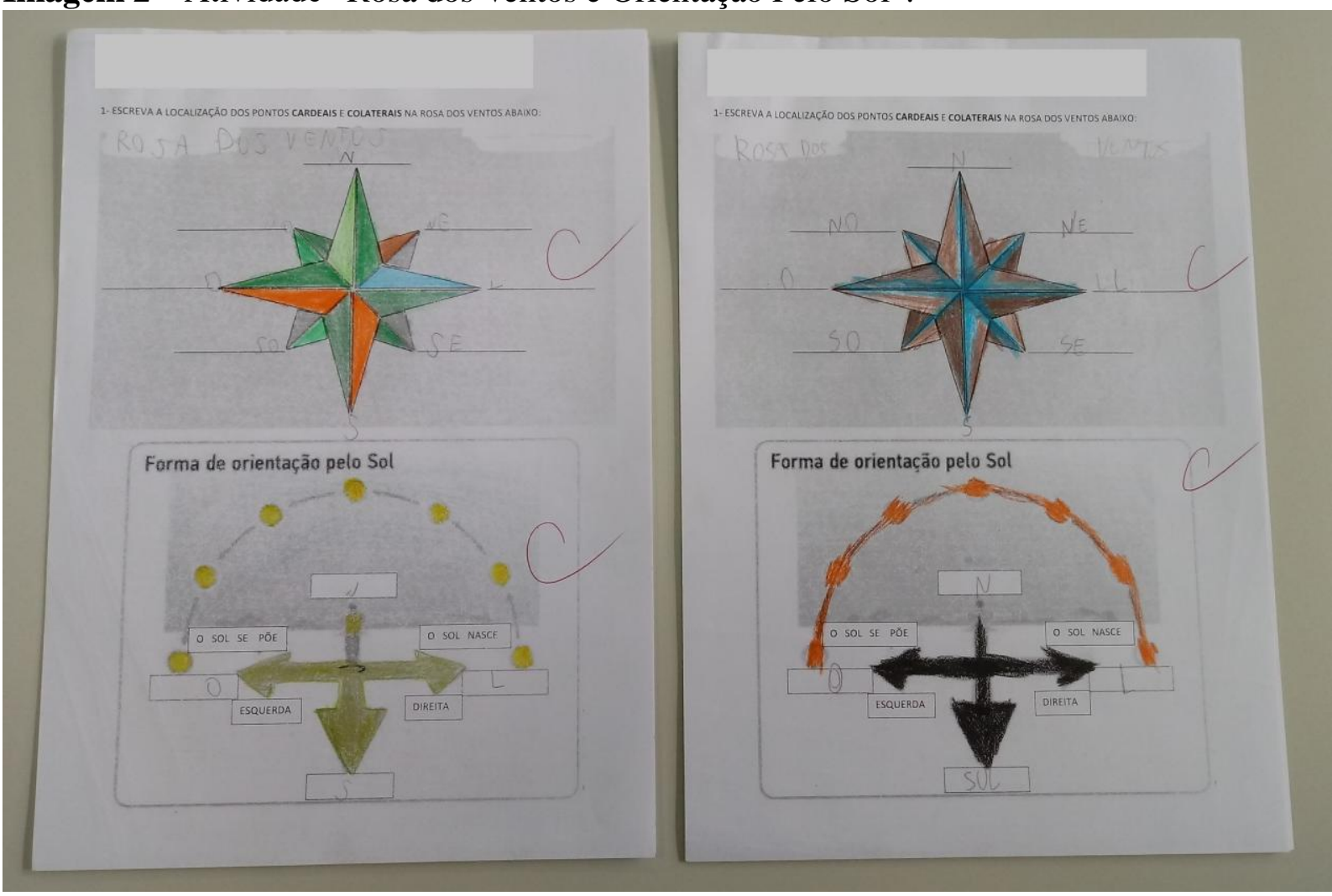

Fonte: Autora.

Dando continuidade à temática central do curso, transformações do espaço geográfico, os alunos assistiram a um dos episódios da série "O mundo sem ninguém" produzido pelo The History Channel. O episódio selecionado, retrata a "América Latina sem ninguém", utilizando animações em 3D e teorias de engenheiros, arquitetos e urbanistas, que demonstram uma

\footnotetext{
${ }^{3}$ Optou-se, em conjunto com as professoras da Apae/Brusque, por selecionar um roteiro com trajeto amplo, entre o centro da cidade e o bairro Volta Grande.
} 
previsão de como seria a América Latina desabitada, quais seriam as marcas deixadas pela sociedade no espaço geográfico. Durante a exibição, em momentos oportunos, foram realizadas pausas para levantar apontamento sobre a temática trabalhada, bem como para estimular nos alunos a reflexão a cerca de: De que maneira transformamos o espaço geográfico? Quais implicações essas transformações podem ocasionar? As transformações provocadas podem acarretar quais consequências negativas e/ou positivas? O que eu posso fazer para minimizar os impactos negativos das minhas ações?

Após trabalhar de diversas maneiras com os alunos o significado de espaço geográfico, procurando utilizar-se de metodologias que contribuíssem para a compreensão, explorou-se os conceitos de lugar e paisagem, respectivamente, considerando-os enquanto conceitos fundamentais para compreender o espaço geográfico e suas transformações ao longo do tempo.

O lugar é entendido aqui enquanto "[...] a base de reprodução da vida e pode ser analisado pela tríade habitante-identidade-lugar." (CARLOS, 2007, p. 17). A paisagem compreende "[...] o domínio do visível, aquilo que a vista abarca. Não é formada apenas de volume, mas também de cores, movimentos, odores, sons etc." (SANTOS, 1988, p. 61).

As explanações sobre os conceitos, sempre iniciou no sentido de questionar os alunos sobre quais eram as suas percepções sobre os mesmos, partindo da sua experiência vivida, do seu dia-a-dia e das suas práticas, para que através disso, na coletividade e ouvindo os demais colegas, fosse possível construir os conceitos.

Sobre o conceito de lugar, através do uso de imagens de diferentes lugares, os alunos foram instigados a observar os seus significados, suas essências, suas características, suas transformações ao longo do tempo, bem como as relações estabelecidas entre lugares próximos e distantes. A partir da observação das imagens, dos apontamentos e questionamentos, partiu-se para a reflexão dos lugares de vivência de cada aluno, para que estes pudessem compreender os significados, os elementos, os fluxos, os sentimentos, os odores, os movimentos, as relações, as transformações e os problemas dos lugares onde vivem.

Durante a explanação do conteúdo realizou-se a seguinte atividade: os alunos dividiram uma folha A4 em 3 partes, sendo que em cada uma das partes registraram através de desenho os conhecimentos adquiridos durante a aula. Na primeira parte registraram um desenho representativo do lugar onde vivem, na segunda registraram um desenho representativo do seu trajeto diário, e na terceira registraram algum problema existente no(s) lugar(es) onde vivem. Na imagem 3 é possível observar um dos resultados dessa atividade.

Depois de concluída a atividade cada aluno explicou o que os seus registros representavam.

Os registros por meio de desenho são importantes para que as pessoas com deficiência intelectual possam assimilar melhor o conhecimento. Haja visto que, no caso dessa turma, apenas alguns alunos sabiam ler e escrever, os demais não sabiam ou o faziam com dificuldade.

Sobre o tema paisagem, através da observação de imagens diversas, os alunos foram instigados a refletir sobre a conceituação teórica de paisagem, seus elementos naturais e sociais ou culturais, as marcas do passado, bem como as mudanças que estas sofrem em decorrência das ações humanas. Desse modo puderam compreender as características e essências das paisagens com as quais convivem diariamente, bem como daquelas que estão distantes do seu espaço de vivência, com as quais tem acesso através de viagens, livros, internet, meios de comunicação, entre outros. Ao analisar essas paisagens, procurou-se levantar além das suas características visíveis (aparência/descrição), também a sua essência, através das relações, movimentos, fluxos e problemas nelas existentes. 
EM

QUESTÃO

V.13 N. $03 \bullet 2020$

pág. 71-83

Imagem 3 - Atividade "Impressões dos Lugares".

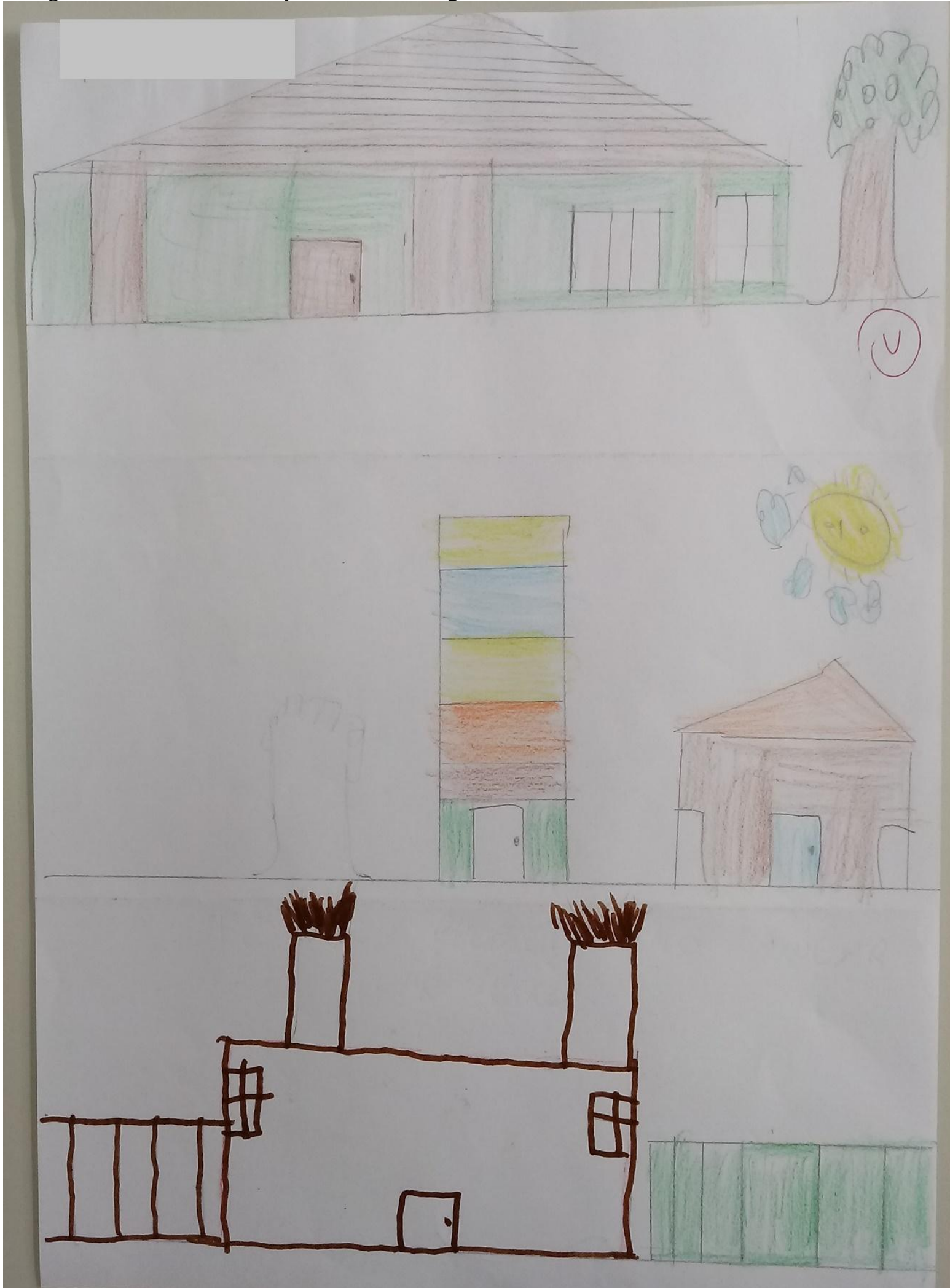

Fonte: Autora.

Para finalizar o curso, trabalhou-se o tema "agrotóxicos". Alinhou-se as concepções de espaço geográfico, lugar e paisagem, entendo o uso de agrotóxicos enquanto ação humana que 
EM

QUESTÃO

V.13 N. $03 \bullet 2020$

pág. 71-83

ocasiona transformações ao espaço, e que inevitavelmente traz consequências maléficas, para o ambiente e para a sociedade.

Inicialmente, através de imagens e esquemas, explicou-se aos alunos o que é o solo, como ele se forma e qual sua importância. Além disso, os alunos observaram quais são os diferentes tipos de solo existentes em Brusque/SC. Posteriormente discutiu-se sobre alguns dos impactos ambientais decorrentes do uso inadequado desse recurso natural, tais como a intensificação dos processos erosivos e a contaminação pelo uso de agrotóxicos. Ao trabalhar especificamente sobre os agrotóxicos, os alunos puderam refletir acerca dos males provocados por estes, ao ambiente (contaminação dos solos, das águas e das plantas) e à sociedade (problemas de saúde), bem como as alternativas possíveis para substituir o uso de agrotóxicos e o consumo de alimentos contaminados, como a agrofloresta, os adubos orgânicos, o controle biológico e os alimentos orgânicos.

Na Apae de Brusque, há um projeto de horta orgânica, desenvolvido por professores da instituição, onde os alunos fazem as atividades de plantio, cuidado e colheita de hortaliças em geral, as quais são consumidas durante as refeições que estes fazem na instituição.

Para melhor fixação do conteúdo, os alunos assistiram ao documentário "O veneno está na mesa II", lançado em 2014. Ele mostra as consequências do uso de agrotóxicos, principalmente para a saúde pública, e apresenta algumas experiências agroecológicas existentes no Brasil, demonstrando que existem alternativas para a produção de alimentos saudáveis e que respeitam a natureza, os trabalhadores do campo e os consumidores.

A atividade desenvolvida, correlacionada a esse conteúdo, foi a confecção de placas com frases de destaque relacionadas à conscientização sobre os benefícios do consumo de alimentos orgânicos. Depois de finalizadas, as placas foram fixadas na horta da Apae. Abaixo, na imagem 4, é possível observar o resultado dessa atividade.

Imagem 4 - Atividade "Conscientização Sobre os Benefícios do Consumo de Alimentos Orgânicos".

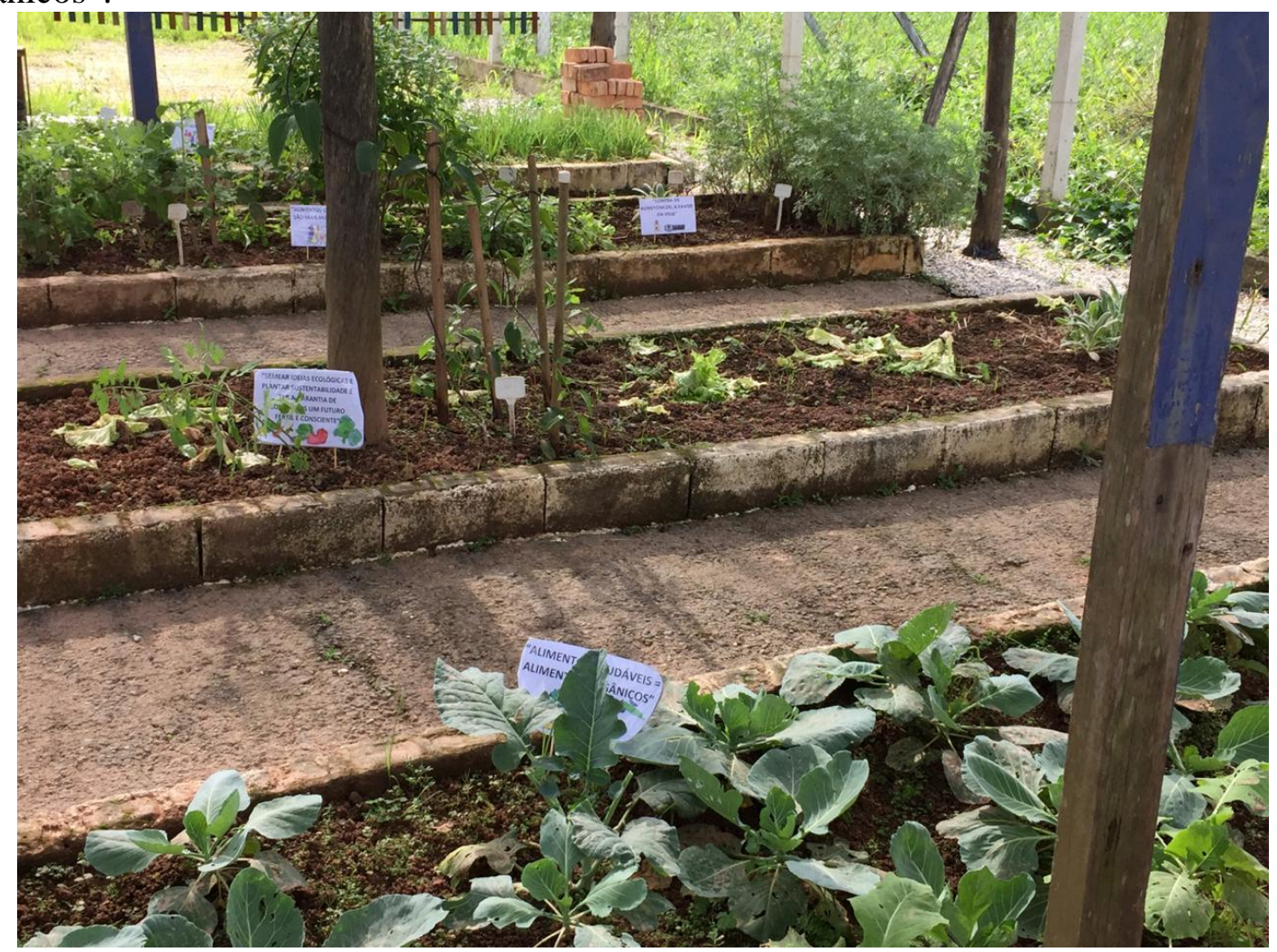

Fonte: Autora. 
Nesse sentido, o curso desenvolvido junto à turma de alunos da Apae, voltada para a qualificação profissional, desdobrou-se em atividades que possibilitaram aos alunos melhor compreensão acerca da Geografia e seu objeto de estudo, o espaço geográfico no qual estão inseridos, das diferentes escalas de análise que compõe este espaço e das transformações inerentes ao mesmo, contribuindo também na questão da locomoção independente. Considera-se que tais desdobramentos proporcionaram a aquisição de conhecimentos e habilidades que contribuirão sobremaneira para a vida em sociedade e também para os desafios do mundo do trabalho.

\section{Contribuições para a inclusão social e profissional através da análise espacial}

Araújo (2006), afirma que independente dos desafios postos pela sociedade atual, a inclusão das pessoas portadora de necessidades especiais deve configurar-se como uma possibilidade concreta na vida destes indivíduos.

Portanto, o curso de qualificação profissional oferecido junto a Apae de Brusque, buscou contribuir para a inclusão social e profissional das pessoas portadoras de necessidades especial atendidas pela instituição, por meio da compreensão das transformações espaciais do seu espaço vivido e de suas práticas espaciais. Tal compreensão se deu pela análise de conceitos fundamentais da Geografia, que proporcionou, simultaneamente, a compreensão da realidade em que os alunos estão inseridos. As reflexões e trocas de experiências realizadas durante o curso contribuíram para o desenvolvimento pessoal e cognitivo dos alunos, o que, por conseguinte, desdobra-se na formação de indivíduos conhecedores, atuantes e transformadores de sua realidade.

Os conceitos fundamentais trabalhados foram: espaço, lugar e paisagem, correlacionados com natureza e sociedade. Outros conceitos, igualmente importantes, não foram trabalhados considerando-se o pouco tempo disponível para desenvolver o curso.

Castellar (2007, p. 86), aponta que "[...] para iniciar o processo de formação de conceitos, é necessário confrontar o estudante com algum problema possível de ser resolvido com a aquisição de novos conceitos [...]" (CASTELLAR, 2007, p. 86). Ao longo do curso, este foi o ponto de partida para a compreensão dos conceitos trabalhados. Partiu-se do conhecimento prévio dos alunos, das suas experiências e práticas espaciais, do seu espaço vivido e conhecido. Através desse ponto de partida, os conceitos geográficos foram continuamente construídos no coletivo e correlacionados com as diferentes vivências e práticas sociais identificadas pelos alunos, bem como avançando para escalas de análise mais amplas, envolvendo os espaços não vividos, mas que de maneira direta ou indireta interferem na vida em sociedade.

Os homens vivem num espaço, situam-se nele, ocupam lugares. Esse espaço comumente é visto como algo estático, pronto e acabado. Tem uma aparência. Mas é resultado de uma dinâmica, é cheio de historicidade. A aparência é o resultado, num determinado momento, de coisas que aconteceram. É a expressão de um processo, portanto há dinâmica no arranjo. Só na aparência ele é estático, pois em si está constantemente sendo construído. E, conhecer o espaço, entendê-lo, é observar esta dinâmica e percebê-lo como resultado, mais do que aceitá-lo como definitivo e acabado. (CALLAI; CALLAI, 2003, p. 69).

Nesse sentido, considera-se que a compreensão das transformações inerentes ao espaço geográfico, adquiridas durante o curso, contribuirão na formação profissional e pessoal dos 
EM

alunos envolvidos, uma vez que lhes permite o conhecimento mais aprofundado da realidade em que estão inseridos, consequentemente esse conhecimento lhes proporcionará uma melhora cognitiva para o mundo do trabalho e para sua inclusão na sociedade. Tendo em vista que a inclusão no mundo do trabalho requer a busca constante por uma formação que capacite, não só na área técnica, mas também em outras áreas que lhe deem suporte ao desempenho de sua formação específica.

Considera-se que as reflexões acerca do seu espaço vivido, atrelada à observação de imagens para além da escala local e conhecida, juntamente com as trocas de experiências, de informações realizadas com os demais colegas em sala, proporcionou aos alunos aprendizados que contribuirão para a sua formação pessoal e profissional. Contribuindo também para que estes tenham uma visão crítica perante à sociedade em que estão inseridos.

Ao discutirmos em sala, os significados de espaço, lugar e paisagem, os alunos perceberam que estes se traduzem nos resultados de suas ações, enquanto seres humanos que transformam os espaços, lugares e paisagens nos quais convivem, direta ou indiretamente. Essa percepção lhes permitiu pensar acerca das possíveis consequências de suas ações, refletindo sobre os impactos delas decorrentes. Assim articulou-se a temática trabalhada em sala com a educação ambiental, tema interdisciplinar e transversal. Sobre a questão ambiental Jacobi (2003) aponta que:

Tomando-se como referência o fato de a maior parte da população brasileira viver em cidades, observa-se uma crescente degradação das condições de vida, refletindo uma crise ambiental. Isto nos remete a uma necessária reflexão sobre os desafios para mudar as formas de pensar e agir em torno da questão ambiental numa perspectiva contemporânea. (JACOBI, 2003, p. 190)

Nesse sentido, os conteúdos trabalhados em sala levaram os alunos a refletir sobre suas formas de pensar e agir em torno também da questão ambiental, apontada por Jacobi (2003) com uma reflexão necessária.

A metodologia utilizada com base na observação de imagens, foi de fundamental importância no processo de ensino aprendizagem, pois possibilitou aos alunos correlacionar o seu espaço vivido com outros espaços, para além da escala local. Sendo que os alunos também puderam analisar a essência das paisagens observadas, suas relações e seus sentidos, e perceber como se diferenciam. Todas essas observações contribuíram no sentido de proporcionar aos alunos compreender que o espaço geográfico é complexo, e que apresenta-se amplamente diferenciado, enquanto resultado das ações humanas, sendo que estas se manifestam em proporções diferentes, haja vista a desigualdade inerente à sociedade que o forma. Buscou-se reafirmar o conceito de espaço geográfico através de Milton Santos, que o define como:

[...] algo dinâmico e unitário, onde se reúnem materialidade e ação humana. O espaço seria o conjunto indissociável de sistemas de objetos, naturais ou fabricados, e de sistemas de ações, deliberadas ou não. A cada época, novos objetos e novas ações vêm juntar-se às outras, modificando o todo, tanto formal quanto substancialmente. (SANTOS, 2008, p. 46).

A observação das cores, sons, odores e movimentos presentes nas imagens representativas dos conceitos geográficos, também contribuiu sobremaneira para a percepção acerca das diferenciações espaciais.

As atividades de elaboração do mapa mental de um trajeto conhecido por eles, e a aula 
de campo desenvolvida em um dos roteiros do transporte coletivo de Brusque, proporcionaram a observação, na prática, das diferenciações espaciais existentes nas áreas central e periférica da cidade, estimulando-os a refletir sobre as razões que levam à essas diferenciações.

Para além disso, Souza; Pereira (2007), apontam que quando o aluno tem a possibilidade de observar a paisagem urbana identificando suas transformações, sua dinâmica, e se percebendo como parte e também produtor deste espaço, tal observação e reflexão contribuem para a sua formação enquanto cidadão.

Ao trabalhar com os alunos um dos episódios da série "O mundo sem ninguém”, estes puderam refletir sobre as marcas que são deixadas pela sociedade no espaço por esta ocupado, bem como conjeturar as implicações e consequências dessas marcas. Tais reflexões os levou a pensar sobre as ações que eles próprios desenvolvem no dia-a-dia e os seus possíveis impactos.

As atividades, sobre os conceitos de lugar e paisagem, realizadas através da elaboração de desenhos, possibilitou aos alunos representar as suas percepções sobre os conteúdos estudados, contribuindo enquanto instrumento para melhor assimilação acerca dos conceitos. O processo de ensino aprendizagem através da expressão artística “[...] se caracteriza como um modo particular de dar sentido às experiências pessoais, por meio das quais o aluno amplia a sensibilidade, a percepção, a reflexão e a imaginação." (MARTINS; GARCIA, 2014, p. 6)

Por fim, a análise do documentário "O veneno está na mesa II", enfatizou novamente as consequências das ações humanas no espaço geográfico, bem como possíveis "caminhos" alternativos. Com essa reflexão, ressaltou-se a importância da horta orgânica cultivada pelos alunos e servidores da Apae. Demonstrando ainda, que existem alterativas para que as transformações provocadas pelos seres humanos ao espaço não sejam tão danosas.

Assim, o curso desenvolvido, se propôs a formar cidadãos críticos e participativos na sociedade técnica e informacional da atualidade, através do apoio educacional à qualificação profissional para a inclusão no mundo do trabalho, contribuindo também para a formação humana integral dos alunos da instituição. Haja visto que esses sujeitos, mediante sua formação pessoal e os possíveis desdobramentos no que se refere à qualificação profissional, resultantes disso, contribuem para o desenvolvimento local e regional, pois tornam-se sujeitos ativos, capazes de atuar nos diferentes segmentos da sociedade.

\section{Considerações finais}

Com base no exposto, considera-se que o curso de qualificação profissional desenvolvido junto aos alunos da Apae de Brusque contribuiu para emancipação e inclusão social destes, tendo em vista que o espaço escolar constitui-se num ambiente que contribui sobremaneira no processo de inclusão e fortalecimento da pessoa com deficiência.

Todas as atividades desenvolvidas foram planejadas no sentido de potencializar as habilidades, experiências e saberes prévios de cada aluno, sendo que as constantes trocas ocorridas em sala, tanto entre os alunos, quando destes para com o professor, foram enriquecedoras, proporcionando a aquisição de conhecimentos e o desenvolvimento de habilidades e competências.

O curso teve como objetivo principal proporcionar aos envolvidos condições para agirem enquanto cidadãos ativos, transformadores de sua realidade, mas buscou-se também que estes se tornassem conhecedores do espaço em que estão inseridos, entendendo-se enquanto atores que criam e transformam esse espaço. Para tanto, explorar os conceitos de 
EM

espaço, lugar e paisagem, foi fundamental.

As metodologias e instrumentos utilizados, priorizando inicialmente o espaço de vivência dos alunos, e avançando para outros espaços através do uso de imagens, de desenhos, de documentários e a realização da aula de campo, permitiram aos alunos a possibilidade de ampliação do conhecimento para além da escala local, do espaço conhecido, contribuindo assim para a melhora cognitiva para a formação pessoal e para o mundo do trabalho.

Considera-se ainda que a parceria existente entre a Associação de pais e amigos dos excepcionais de Brusque e o Instituto Federal Catarinense - Campus Brusque é extremamente enriquecedora para ambas as instituições, pois permite a aquisição não apenas de conhecimento, por parte dos alunos envolvidos, mas também por parte dos professores, que podem enriquecer sua prática pedagógica.

Assim, o curso desenvolvido em parceria com a Apae colaborou para que os sujeitos envolvidos pudessem adquirir conhecimentos geográficos que contribuem para sua formação pessoal, para a vida em sociedade, bem como para a atuação profissional.

\section{Referências}

ARAÚJO, Luiz Alberto David (Org.) Defesa dos direitos das pessoas portadoras de deficiência. São Paulo: Editora Revista dos Tribunais, 2006.

CALLAI, Helena Copetti; CALLAI, Jaeme Luiz. Grupo, espaço e tempo nas séries iniciais. In: CASTROGIOVANNI, A. C. et al. (orgs.) Geografia em sala de aula: práticas e reflexões. 4. ed. Porto Alegre: UFRGS, 2003, p. 163-167.

CARLOS, Ana Fani Alessandri. O lugar no/do mundo. São Paulo: FFLCH, 2007.

CASTELlAR, Sonia Maria Vanzella. (org). Educação geográfica: teorias e práticas docentes. $2^{\circ}$. ed. São Paulo: Contexto, 2007.

FRANCIOSI, Rosilene Rodrigues Martins; TORRES, Eloiza Cristiane. A geografia para alunos com necessidades especiais: orientação espacial a partir da escala local por meio de maquete. Cadernos PDE. Versão online, v. 1. p.2-21, 2013. Disponível em: <http://www.diaadiaeducacao.pr.gov.br/portals/cadernospde/pdebusca/producoes_pde/2013/2 013_uel_geo_artigo_rosilene_rodrigues_martins_franciosi.pdf $>$. Acesso em: 16 nov. 2018.

JACOBI, Pedro. Educação ambiental, cidadania e sustentabilidade. Cadernos de Pesquisa, São Paulo, n. 118, p. 189-205, mar. 2003. Disponível em: <http://www.scielo.br/pdf/cp/n118/16834.pdf >. Acesso em: 16 nov. 2018.

MARTINS, Soely de Fátima Antunes; GARCIA, Cláudio Luiz. O desenho no ensino fundamental. Cadernos PDE. Versão online, v. 1. p.2-24, 2014. Disponível em: <http://www.diaadiaeducacao.pr.gov.br/portals/cadernospde/pdebusca/producoes_pde/2014/2 014_uel_arte_artigo_soely_de_fatima_antunes_martins.pdf>. Acesso em: 16 nov. 2018.

SANTOS, Minton. Técnica, Espaço, Tempo: Globalização e meio técnico-científicoinformacional. São Paulo: Editora da Universidade de São Paulo, 2008. 
Metamorfoses do espaço habitado. São Paulo: Hucitec, 1988.

Por uma Geografia Nova. São Paulo: Hucitec, Edusp, 1978.

SOUZA, José Carlos de; PEREIRA, Rodrigo Magalhães. Uma reflexão acerca da importância do trabalho de campo e sua aplicabilidade no ensino de geografia. Disponível

em:

$<$ https://observatoriogeogoias.iesa.ufg.br/up/215/o/uma_reflexao_acerca_da_importancia_do_ trabalho_de_campo.pdf $>$. Acesso em: 16 nov. 2018.

Artigo recebido em 01-10-2019

Artigo aceito para publicação em 05-08-2020 